\title{
Development of a Patient Reported Experience Measure (PREM) for use in the ambulance service
}

UNIVERSITY OF LINCOLN

\section{Introduction}

NHS health policy emphasises the crucial role of patient experience as a core component of high quality care, alongside effectiveness and safety. In order to measure patient experience, brief selfcompletion questionnaires called Patient Reported Experience Measures (PREMs) have been developed for use in a variety of healthcare settings. They are increasingly being seen as valuable for assessing patient outcomes and differences in quality between health care providers.

There are a number of PREMs that can capture patient views about primary care and elective inpatient treatment, but as yet there is no generally used PREM for ambulance service care. Neither have patient surveys to assess ambulance service care been routinely implemented or standardised. This study forms one part of doctoral research to develop a PREM for use in UK ambulance services.

\section{Methods}

The study comprised three work streams:

-A secondary qualitative analysis of 44 interviews that explored patients' experiences of their ambulance service care

-Development of questionnaire items based on the themes emerging from the secondary analysis

-Semi-structured interviews with service users that explore their opinions of the questionnaire items and whether the PREM incorporates all aspects of the ambulance service experience that should be included.

\section{Results \\ The secondary data analysis revealed two types of themes: 'processes of importance' and 'experiential'.}

\section{Processes of importance:}

timeliness, communication, professional and transfer of care between services.

\section{Experiential:}

reassurance, clinicians conduct and patient centred care.

These key themes formed the foundation for generating a $\mathbf{5 3}$ item questionnaire. Six semi-structured interviews were undertaken with previous patients of the ambulance service to explore their views of the draft PREM. The data obtained are being used to amend the questionnaire items with regard to content, formatting and response types.

Themes, supporting quotations and corresponding draft PREM items

\begin{tabular}{|c|c|c|}
\hline Theme & Supporting quotation & Questionnaire item \\
\hline \multicolumn{3}{|c|}{ Processes of importance: } \\
\hline Timeliness & $\begin{array}{l}\text { The speed in which they came was quite } \\
\text { good and certainly the way he was as a } \\
\text { person, I couldn't have faulted him (P15, } \\
\text { PhOEBE, See \& Treat) }\end{array}$ & $\begin{array}{l}\text { The length of time I waited for help to arrive was acceptable } \\
\text { a) Yes, the length of time I waited was acceptable } \\
\text { b) No, the length of time I waited was not acceptable } \\
\text { c) Don't know/can't remember }\end{array}$ \\
\hline Communication & $\begin{array}{l}\text { "...they were quite humorous, there was } \\
\text { a lot of humour with them. They were just } \\
\text { lovely people, they're like a breed of their } \\
\text { own I think" (P21, ISPROVE, AMI) }\end{array}$ & $\begin{array}{l}\text { Were you happy with how the ambulance crew spoke with you? } \\
\text { a) Yes, completely } \\
\text { b) Yes, to some extent } \\
\text { c) No, I was not happy } \\
\text { d) Don't know/can't remember }\end{array}$ \\
\hline \multicolumn{3}{|l|}{ Experiential: } \\
\hline Reassurance & $\begin{array}{l}\text { "It's when you get scared and you can't } \\
\text { breathe and you think 'ah well this is } \\
\text { it'... but the minute that ambulance draws } \\
\text { up in my drive I feel quite relaxed and } \\
\text { relieved ...I'm in the best hands I could } \\
\text { be.(P5, ISPROVE, AMI) }\end{array}$ & $\begin{array}{l}\text { I felt reassured I felt reassured by the ambulance crew } \\
\text { a) Yes, completely } \\
\text { b) Yes, to some extent } \\
\text { c) No, I did not feel reassured } \\
\text { d) Don't know/can't remember }\end{array}$ \\
\hline Clinicians' conduct & $\begin{array}{l}\text { It's...it's...I suppose it's } \\
\text { more psychological isn't } \\
\text { really? You know you're in } \\
\text { safe hands. Even if I pass } \\
\text { out... They're here. (P14, PhOEBE, } \\
\text { See \& Convey) }\end{array}$ & $\begin{array}{l}\text { The ambulance crew made me feel safe } \\
\text { a) Yes, completely } \\
\text { b) Yes, to some extent } \\
\text { c) No, they did not make me feel safe } \\
\text { d) Don't know/can't remember }\end{array}$ \\
\hline
\end{tabular}

\section{Conclusions}

The preliminary construction of the PREM has incorporated the views of patients (from both the secondary data analysis and interviews) for whom the measure is ultimately designed.

Once completed, the PREM will enable ambulance trusts to measure differences in patient experiences, between and within organisations. Appropriate implementation will result in positive changes to patient experience through the introduction of feedback, training and education to ambulance service clinicians.

\section{Future research}

The next stage of this doctoral research will involve recruiting prehospital experts to evaluate the modified PREM using a verified structured checklist. The final stage of the PhD will involve the recruitment of patients to cognitive interviews that will explore how patients perceive and interpret the questionnaire.

In order to assess the validity and reliability of the finalised PREM pilot testing of the tool in a clinical setting would be required. It is expected that a research funding bid will be submitted to ensure that this important work can be carried out. 